\title{
PENGARUH PEMBELAJARAN KEPERAWATAN ANAK DENGAN VIDEO FOTOTERAPI TERHADAP TINGKAT PENGETAHUAN
}

\section{The Effect of Child Nursing Learning with Video Phototherapy on Knowledge Level}

\author{
Marcellina Rasemi Widayanti, Irine Yunila Prastyawati, Agnes Putri Natalia
}

STIKES Katolik St. Vincentius a Paulo Surabaya

\section{Riwayat artikel}

Diajukan: 23 Maret 2021

Diterima: 20 Mei 2021

\section{Penulis Korespondensi: \\ - Irine Yunila Prastyawati \\ - STIKES Katolik St. \\ Vincentius a Paulo \\ Surabaya \\ e-mail: \\ nilastikesrkz@gmail.com}

\section{Kata Kunci:}

Pembelajaran, Video, Keperawatan Anak

\begin{abstract}
Abstrak
Pendahuluan : Pembelajaran mahasiswa keperawatan di STIKES Katolik pada masa pandemi, mayoritas menggunakan metode daring, demikian pula dengan kegiatan pembelajaran praktik dilaboratorium. Salah satu cara yang digunakan sebagai pengganti adalah dengan pembuatan video ketrampilan memasang fototerapi, dengan harapan mahasiswa keperawatan mendapat gambaran tentang prosedur dari ketrampilan tersebut, sehingga mampu mendapatkan hasil belajar yang maksimal, untuk mengingat Kembali video dapat diputar ulang oleh mahasiswa keperawatan. Metode: Desain dalam penelitian ini adalah pra-experiment, dengan populasi mahasiswa semester V Prodi Ilmu Keperawatan STIKES Katolik St.Vincentius a Paulo Surabaya, pengambilan data, menggunakan sampling jenuh, semua mahasiswa digunakan sebagai sampel jumlahnya 35 responden, Variabel bebas dalam penelitian adalah pembelajaran menggunakan video, variable terikat yaitu tingkat pengetahuannya dalam memasang fototerapi. Data dikumpulkan menggunakan kuesioner mengenai persiapan \& penatalaksaan pemasangan fototherapi sebelum dan setelah melihat video fototherapi yang sudah disiapkan, sehingga dapat menilai pemahaman/ pengetahuan mahasiswa keperawatan. Hasil: Hasil dari Analisa Statistik Deskriptif Proporsi Prosentase didapatkan sebelum melihat video Sebagian besar $(51,43 \%)$ hasil belajarnya masuk kategori tingkat pengetahuan cukup, setelah melihat video pembelajaran mayoritas (91,43\%) tingkat pengetahuannya adalah baik, dari uji statistic Wilcoxon dengan tingkat signifikan $\alpha=0.05$ dan didapatkan harga $\mathrm{p}=0.005$ maka $\mathrm{p}<\alpha$ maka H1 diterima, artinya ada pengaruh tingkat pengetahuan mahasiswa sebelum dan setelah pembelajaran menggunakan video memasang fototerapi. Kesimpulan: Berdasarkan hasil diatas maka selama pembelajaran daring, sebagai pengganti praktik dilaboratorium dapat menggunakan video untuk membantu mahasiswa belajar mengenai ketrampilan, walaupun tidak dipraktikkan, sehingga mahasiswa mempunyai gambaran tentang prosedur yang seharusnya dipraktikkan.
\end{abstract}

\section{Abstract}

Background: Learning during the pandemic, the majority used online methods, as well as practical learning activities in the laboratory. One of the ways used as a substitute is by making a video of the skills to install phototherapy with the hope that students will get an idea of the procedure of the skill, so that they can get maximum learning outcomes, to recall the video can be played back.Method The design in this study was a pre-experiment, with a population of fifth semester students of the Nursing Study Program at STIKES Catholic St. Vincent de Paul Surabaya, data collection, using saturated sampling, all students were used as samples, the number of which was 35 respondents, the independent variable in the study was learning using video, the dependent variable is the level of knowledge in applying phototherapy. Data were collected using a questionnaire before and after viewing the video. The results of the ASDPP were obtained before viewing the video. The most (51.43\%) of the learning outcomes were in the sufficient level of knowledge category, after seeing the learning videos the majority (91.43\%) the level of knowledge was good, from the Wilcoxon statistical test with a significant level of $\alpha=0.05$ and obtained price $p=0.005$ then $p<\alpha$ then H1 is accepted, meaning that there is an influence on the level of student knowledge before and after learning to use video to install phototherapy. Conclusion: Based on the above results, during online learning, as a substitute for practice in the laboratory, videos can be used to help students learn about skills, even though they are not applied, so that students have an idea of the procedures that should be practiced. 


\section{PENDAHULUAN}

Pembelajaran secara normal merupakan pertemuan / tatap muka antara pendidik dengan peserta didik. Dimana dalam pertemuan tersebut terdapat suatu proses atau kegiatan interaksi antara peserta didik, pendidik dan menggunakan sarana media(MENTERI RISET, TEKNOLOGI \& INDONESIA No 44, 2015). Melalui interaksi yang terjadi, peserta didik dapat mempelajari berbagai macam ilmu dan bersosialisasi dengan lingkungannya, sehingga akhir pembelajaran dapat meningkatkan pemahaman/ pengetahuan peserta didik meliputi Intelegensi dan kecerdasan emosi. Pendidikan memiliki tujuan dasar yaitu dapat mempengaruhi mahasiswa menuju perubahan tingkah laku secara intelektual, moral maupun sosial (Arsyad, 2016). Adanya Pandemi covid-19 pembelajaran dikelas (tatap muka) tidak diperkenankan dilakukan, dengan alasan mencegah terjadinya penularan pada cluster sekolah/kampus, demi menjaga keselamatan dan keamanan peserta didik/ mahasiswa / pendidik maka pembelajaran disekolah disarankan menggunakan sistem online atau virtual (yang berhubungan dengan teknologi dan internet) tanpa adanya tatap muka secara langsung yang lebih dikenal dengan istilah system pembelajaran dalam jaringan (daring) sebagai pengganti kata online. Proses pembelajaran daring dilakukan dengan menggunakan platform yang telah tersedia. Semua materi kuliah dan ujian didistribusikan melalui online yang dibantu dengan beberapa aplikasi, misalnya Google Classroom, Google Meet, Zoom, dan lain sebagainya. Yang menjadi masalah tidak semua materi ketrampilan dapat pelajari dengan baik oleh peserta didik, demikian pula dengan pembelajaran praktik di ruang laboratorium tidak dapat dilaksanakan karena peserta didik tidak diijinkan datang ke sekolah/ kampus..

Survei yang dilakukan pada 20 peserta didik/mahasiswa pada bulan Juni 2020, hasilnya mereka menyampaikan $60 \%$ pembelajaran menggunakan zoom/ google meet kadang terhambat dengan jaringan (hilang timbul) baik di luar jawa maupun di jawa, salah satu penyebabnya adalah kendala cuaca sehingga tidak dapat mengikuti secara lengkap dan mahasiswa mengharapkan bisa menerima pembelajaran seperti biasanya supaya dapat belajar terutama mengenai ketrampilan di ruang laboratorium, selama pandemic kegiatan ini tidak dapat dilakukan oleh mahasiswa, sedangkan Latihan ketrampilan mutlak harus dijalani oleh peserta didik sebagai bekal pada saat praktik pada tatanan nyata. $40 \%$ mengatakan kurang jelas dalam menerima materi walaupun sudah mendapat penjelasan \& materinya, kalau dikelas bisa menanyakan pada dosen atau teman secara langsung. Pada prinsipnya semua pembelajaran terdapat kekurangan dan kelebihan, sebagai pendidik mencoba untuk meminimalkan adanya kekurangan dalam proses pembelajaran.. Berdasarkan hasil penelitian sebelumnya (Ferazona et al., 2020), metode pembelajaran daring yang didalamnya menggunkan media video pembelajaran akan dapat memberikan semangat kepada mahsiswa, dimana pemberian video mahasisiwa dapat mengulang kembali untuk belajar tanpa harus perlu jaringan internet langsung.

Pada proses pembelajaran beberapa faktor yang mempengaruhi belajar antara lain kondisi internal dan eksternal dari peserta didik, misalnya unttuk factor internal karena sakit, Lelah dll maka proses belajar juga tidak maksimal, demikian pula dengan masalah eksternal misalnya ada masalah didalam keluarga, jauh dari teman materi pembelajaran yang sulit dipahami, tidak menarik, membosankan . Beberapa permasalahan tersebut sangat menggangu dalam penerimaan materi belajar, sehingga pada akhirnya akan mempengarruhi terhadap hasil/prestasi belajar perserta didik. Demikian pula dengan pembelajaran yang membutuhkan praktik, peserta didik selain diberi contoh dengan metode demonstrasi \& harus diberi kesempatan untuk mencoba, karena capaian belajar yang diharapkan adalah mampu menerapkan, tetapi kondisi pandemic pendidik untuk sementara belum bisa mengajak peserta didik kekampus.

Menurut Peraturan Pemerintah nomor 44 tahun 2015 tentang standar nasional pendidikan tinggi menyatakan bahwa pembelajaran pada satuan pendidikan diselenggarakan secara 
interaktif, inspiratif, menyenangkan, menantang, memotivasi peserta didik untuk berpartisipasi aktif, kreatifitas serta kemandirian sesuai dengan bakat, minat serta psikologis peserta didik. Tujuan tersebut dapat dicapai melalui optimalisasi tenaga pendidik/dosen yang profesional yang memiliki kemampuan dalam bidang pembelajaran, sehingga peran pendidik dituntut untuk terus mampu menguasai materi pelajaran yang akan diajarkan dan trampil dalam proses menyajikannnya. Diharapkan pendidik memilih dan menggunakan metode pembelajaran yang sesuai serta trampil dalam menggunakan media pembelajaran. Pembelajaran ketrampilan bukan hanya dengan metode ceramah tetapi sebaiknya disertai dengan gambar untuk memperjelas, menurut Rossi \& Breidle yang dikutip oleh Sanjaya (2012) media pembelajaran adalah semua alat dan bahan yang dapat dipergunakan untuk tujuan pendidikan, misalnya video, radio, televisi, buku, laptop dan lainnya. Media pembelajaran merupakan salah satu sarana non personal (bukan manusia) yang digunakan pengajar untuk mencapai tujuan instruksional pembelajaran. Contoh dari media pembelajaran adalah audiovisual yang merupakan perkembangan dari teknologi elektronika dan mekanika. Video merupakan salah satu media yang dapat merekam ketrampilan/ prosedur mengenai Tindakan pemasangan fototherapi, sehingga dengan melihat prosedur pemasangan fototherapi melalui video harapan pendidik sebagai pengganti sementara kegiatan demonstrasi di ruang laboratorium kelas. Pada mahasiswa semester V salah satu mata ajarnya adalah keperawatan anak untuk metode demonstrasi ketrampilan dicoba menggunakan video,hal ini untuk merangsang mahasiswa lebih antusias dalam belajar, karena media tersebut dapat membimbing dengan sabar, maksudnya dapat di putar berulang-ulang. Untuk mencapai hal tersebut maka tiap pendidik/dosen pengajar ketrampilan keperawatan dapat melakukan inovasi dengan membuat model-model pembelajaran multimedia yang dapat dimanfaatkan untuk memperjelas kompetensi ketrampilan yang akan dicapai, guna meningkatkan kualitas lulusan peserta didik Stikes Katolik St Vincentius a Paulo Surabaya. Tujuan dari penelitian ini adalah Mengetahui tingkat pengetahuan sebelum dan setelah melihat video pemasangan fototerapi pada mahasiswa semester V Prodi Ilmu Keperawatan STIKES Katolik St Vincentius a Paulo Surabaya. respondennya mhs smt $\mathrm{V}$ terkait dengan implementasi/penyampaian materi pembelajaran keperawatan anak pada semester tersebut dan juga mereka sebelumnya sudah mendapatkan teori dasar terkait keperawatan

\section{METODE}

Jenis penelitian ini merupakan pra eksperimental dengan rancangan one group pra-post test design. Sampel penelitian ini adalah mahasiswa semester $\mathrm{V}$ prodi ilmu keperawatan STIKES Katolik St. Vincentius a Paulo Surabaya yang berjumlah 35 orang. Teknik pengambilan sampel pada penelitian ini adalah sampling jenuh yaitu suatu cara pengambilan sampel dimana jumlah sampelnya sama dengan populasi

Penelitian dilakukan di STIKES Katolik St. Vincentius a Paulo Surabaya, pada tanggal 17-18 Juni 2020. Data diambil secara langsung pada responden dengan memberikan kuesioner, yang meliputi data demografi secara umum, dan kuesioner pemasangan fototerapi yang sudah dilakukan uji validitas dan reliabilitas.Instrumen ini digunakan untuk mengukur tingkat pengetahuan persiapan \& prosedur pemasangan fototherapi pada mahasiswa sebelum dan setelah melihat video pemasang foto terapi. Instrumen ini terdiri persiapan alat dan prosedur pemasangan foto terapi dikirimkan setelah mahasiswa/ responden mengisi kuesioner pertama (sebelum melihat video). Pada penelitian ini SPSS (statistical product and 
service solution) dengan versi 16 digunakan dalam uji validitas, reliabilitas dan mengolah data dengan menggunakan uji Wilcoxon Signed Ranks Pairs Test

\section{HASIL DAN PEMBAHASAN HASIL}

Tabel 1. Karakteristik responden penelitian

\begin{tabular}{lcc}
\hline Variabel & Frekuensi & Persentase (\%) \\
\hline Jenis kelamin & & \\
Perempuan & 34 & $97 \%$ \\
Laki-laki & 1 & $3 \%$ \\
Usia & & \\
$21-30$ tahun & 35 & $100 \%$ \\
>30 tahun & & $0 \%$ \\
\hline
\end{tabular}

Sumber: (Data Primer, 2020)

Tabel 1 menunjukkan jumlah seluruh responden 35 mahasiswa semester V program studi Ilmu Keperawatan 97 \% (34 reponden) jenis kelaminnya perempuan. Dilihat dari usia $100 \%$ (35 responden) rentang usianya 21 - 30 tahun

Tabel 2. Tingkat pengetahuan responden

\begin{tabular}{lcc}
\multicolumn{3}{c}{ sebelum dilakukan tindakan } \\
\hline $\begin{array}{c}\text { Indikator } \\
\text { Tingkat } \\
\text { Pengetahuan }\end{array}$ & $\begin{array}{c}\text { Frekuensi } \\
(\mathbf{n})\end{array}$ & $\begin{array}{c}\text { Persentase } \\
(\boldsymbol{\%})\end{array}$ \\
\hline Baik & 11 & $31,43 \%$ \\
Cukup & 18 & $51,43 \%$ \\
Kurang & 6 & $17,14 \%$ \\
\hline \multicolumn{1}{c}{ Total } & 35 & $100 \%$ \\
\hline
\end{tabular}

Sumber: (Data Primer, 2020)

Tabel 2 menunjukkan tingkat pengetahuan mahasiswa semester $\mathrm{V}$ sebelum melihat video pembelajaran $51,43 \%$ (18 mahasiswa) tingkat pengetahuannya adalah cukup

Tabel 3. Tingkat pengetahuan responden setelah dilakukan tindakan

\begin{tabular}{lcc}
\hline $\begin{array}{c}\text { Indikator } \\
\text { Tingkat } \\
\text { Pengetahuan }\end{array}$ & $\begin{array}{c}\text { Frekuensi } \\
(\mathbf{n})\end{array}$ & $\begin{array}{c}\text { Persentase } \\
(\boldsymbol{\%})\end{array}$ \\
\hline Baik & 32 & $91,43 \%$ \\
Cukup & 3 & $8,57 \%$ \\
Kurang & 0 & $0 \%$ \\
\hline \multicolumn{1}{c}{ Total } & 35 & $100 \%$ \\
\hline
\end{tabular}

Sumber: (Data Primer, 2020)
Tabel 3 menunjukkan tingkat pengetahuan setelah belajar menggunakan video pembelajaran mengenai pemasangan fototerapi 91,43\% (32) mahasiswa masuk pada kategori kelompok dengan tingkat pengetahuan baik. Uji statistik menggunakan uji wilcoxon yang diolah dengan SPSS 16 untuk mengetahui pengaruh pembelajaran menggunakan video pemasangan fototerapi pada mahasiswa semester $\mathrm{V}$ dengan cara mencari perbedaan pengetahuan mahasiswa sebelum dan sesudah dilakukan pembelajaran dengan video. Hasil uji statistik dengan signifikasi $\alpha=0.05$, didapatkan nilai $\mathrm{p}=0.005$. Harga $\mathrm{p}<\alpha$, maka Ho ditolak, artinya ada pengaruh pembelajaran sebelum dan setelah menggunakan video pemasangan fototerapi pada mahasiswa, dimana setelah melihat video hasil belajar (tingkat pengetahuannya) menjadi lebih baik

\section{PEMBAHASAN}

Ketrampilan pemasangan fototherapi merupakan salah satu ketrampilan pada mata ajar keperawatan anak perlu diakuasai oleh mahasiswa. Ketrampilan ini diharapkan dapat membantu belajar mahasiswa, karena peserta didik dapat mendengar \& melihat gambar pada video. Tingkat pengetahuan mahasiswa sebelum melihat video pembelajaran prosedur pemasangan fototherapi yang paling menonjol adalah tingkat pengetahuan cukup $(51,43 \%)$ juga didapatkan yang masuk pada kategori pengetahuan kurang $(17,14 \%)$. Hal ini disebabkan karena mahasiswa belum memiliki pengetahuan serta pengalaman mengenai ketrampilan pemasangan fototerapi serta kondisi mahasiswa saat ini harus belajar secara mandiri / daring, tidak bisa bertemu dengan pengajar secara langsung karena situasi pandemi mahasiswa tidak belajar dikampus sehingga pembelajaran kurang efektif, ketika dilakukan evaluasi hasilnya kurang maksimal. Beberapa mahasiswa 
mengatakan penah melihat dari internet dengan mempersepsikan sendiri, sehingga tidak mengetahui benar atau salah. Pembelajaran dipengaruhi oleh banyak faktor misalnya faktor jasmaniah dalam proses belajar akan terganggu jika individu tersebut tidak sehat, demikian pula saat seseorang tersebut menderita cacat. Dari sudut Psikologi juga berpengaruh antara lain Inteligensi, perhatian, minat, bakat, motivasi, kematangan dan kelelahan. Semua faktor diatas tidak bisa diabaikan, karena faktor tersebut sangat mempenaruhi proses pembelajaran

Pengetahuan memiliki sifat secara terpadu yang terdiri dari 1) experiential knowledge, 2) skill dan 3) knowledge claim ((Erice et al., 2012). Experiential knowledge diperoleh seseorang melalui hubungan langsung dengan lingkungan lewat sistem sensori, kemudian diproses oleh otak, sehingga pengetahuan didasarkan atas perspektif masing - masing individu. Skill atau keterampilan merupakan pengetahuan bagaimana melakukan sesuatu. Ketrampilan ini didasarkan pada pengetahuan yang terstruktur dan memiliki orientasi tindakan, dimana semakin banyak melakukan suatu tindakan maka akan memiliki pengetahuan dengan ketrampilan yang memadai. Knowledge claim merupakan pengetahuan yang telah kita ketahui, pengetahuan bersifat eksplisit berada dibawah alam sadar seseorang. Setelah dilakukan pembelajaran menggunakan video hasilnya tingkat pengetahuan meningkat menjadi baik yaitu 91,43\% (32 mahasiswa). Mahasiswa menyatakan dengan adanya ketrampilan prosedur pemasangan fototherapi yang dikemas dengan video, mereka lebih paham $\&$ dapat melihat prosedur sesuai dengan langkah-langkahnya, selain itu video dapat diputar ulang untuk mengingat kembali. Pembelajaran menggunakan multimedia (video) atau gambar bergerak memiliki beberapa manfaat antara lain dapat menarik serta mengarahkan perhatian peserta didik dalam hal konsentrasi kepada isi pelajaran, ini memiliki kaitan dengan makna visual yang ditampilkan bersamaan teks materi pembelajaran. Hal tersebuti sesuai dengan penelitian Wiechetek, L. (2018) yang mengatakan bahwa video tidak hanya digunakan untuk hiburam, melainkan juga untuk meningkatkan pengertahuan dan keterampilan serta menciptakan suatu sikap yang benar. Selain itu media visual juga mendorong mahasiswa ketika belajar, karena dapat menggugah emosi dan sikap mahasiswa. Dari temuan-temuan penelitian mengungkapkan bahwa lambang visual atau gambar dapat mempermudah pencapaian tujuan dalam memahami dan mengingat informasi atau pesan yang terkandung dalam gambar. Media fisual juga memiliki fungsi kompensatoris, yaitu dapat memberikan konteks untuk memahami teks sehingga membantu mahasiswa yang lemah dalam membaca untuk mengorganisasikan kata serta mengingat kembali. Media pembelajaran ini dengan kata lain memiliki fungsi untuk mengakomodasi mahasiswa yang lemah dan lambat

Hasil uji statistik dengan signifikasi $\alpha$ $=0.05$, didapatkan harga $\mathrm{p}=0.005$. Harga $\mathrm{p}$ $<\alpha$, maka Ho ditolak, artinya ada pengaruh pembelajaran sebelum dan setelah menggunakan video pemasangan fototerapi pada mahasiswa, dimana setelah melihat video hasil belajar (tingkat pengetahuannya) menjadi lebih baik. Menurut Rossi \& Breidle yang dikutip oleh Sanjaya (2012) Media pembelajaran merupakan alat dan bahan yang digunakan untuk tujuan pendidikan, misalnya radio, televisi, buku, laptop dan sebagainya. Media pendidikan diartikan sebagai suatu sarana non personal (bukan manusia) yang digunakan atau disediakan oleh pengajar untuk mencapai tujuan instruksional. Misalnya audiovisual yang merupakan perkembangan dari teknologi elektronika dan mekanika. Pernyataan tersebut penulis terapkan pada penelitian ini, karena pada masa pandemi 
mahasiswa tidak diperkenankan belajar dikampus dengan alasan mencegah terjadinya penularan Covid-19, untuk menggantikan pembelajaran dilaboratorium kampus menggunakan Video yang dibuat oleh pengajar untuk dikirim pada mahasiswa, sehingga mahasiswa dapat mempelajari materi ketrampilan pemasangan fototerapi secara mandiri, tiap mahasiswa dapat belajar dengan cara mengamati video, yang dapat diputar ulang untuk mengingat kembali. Video mereka memberikan beberapa keuntungan bagi mahasiswa seperti dapat mengendalikan kecepatan belajar mereka, namun informasi dan kontrol peserta didik dapat meningkatkan beban kognitif dan disorientasi peserta didik, terutama untuk peserta didik dengan pengetahuan sebelumnya yang rendah ( $\mathrm{Yu} \mathrm{Li}, 2018)$. Respon dari mahasiswa juga positif, mereka menyampaikan bahwa pembelajaran dengan video menyenangkan dan sangat membantu selain itu juga tidak perlu kehadiran dosen sehingga mahasiswa dapat mandiri serta tidak terikat waktu belajarnya KESIMPULAN

Terdapat pengaruh pembelajaran sebelum dan setelah melihat video mengenai pemasangan foto terapi pada mahasiswa semester V Prodi Ilmu Keperawatan STIKES Katolik St. Vincentius a Paulo Surabaya. Pada kondisi pandemi pembelajaran kegiatan praktik dilaboratorium tidak memungkinkan untuk dilaksanakan, karena dikawatirkan terjadinya penularan Covid-19. Hasil penelitian diatas dapat membantu dalam pencapaian hasil belajar yaitu dengan penggunaan video sebagai ganti dari pembelajaran diruang laboratoium, sehingga mahasiswa mempunyai gambaran mengenai prosedur/ ketrampilan yang nantinya dapat digunakan pada saat mahasiswa harus praktik pada tatanan nyata
Arsyad, Azhar (2016). Media Pembelajaran. Jakarta: PT Raja Grafindo Persada.

Bolisani, E. and Bratianu, C. (2018) 'Emergent Knowledge Strategies', Emergent Knowledge Strategies, 4(July), pp. 23-47. doi: 10.1007/9783-319-60657- 6.

Erice, D. B., Questier, F., Luján, D. P., \& Zhu, C. (2012). Linking E-learning Tools with Experiential Knowledge Production in Higher Education Teaching-learning Processes: The Case of Open Source LMS. International Journal of Information and Education Technology, 2(4), 327-330.

https://doi.org/10.7763/ijiet.2012.v2. 143

Ferazona, S., Biologi, P., \& Riau, U. I. (2020). Pengaruh Pembelajaran Daring terhadap Hasil Belajar. Journal of Research and Education Chemistry, 2(2), 102-110. https://doi.org/10.25299/jrec.2020.vo 12(2).5826

Menteri riset, teknologi, d. P. T., \& indonesia, r. (2015). Standar nasional pendidikan tinggi.

Sanjaya, Wina.(2012). Strategi

Pembelajaran. Jakarta:

Jakarta:Kencana Prenada Media Group

Wiechetek, Lukasz. (2018). Improving knowledge and skills with videosharing websites. Framework of elearning video course for students of logistics. doi: $10.21125 /$ inted.2018.0388

$\mathrm{Yu} \mathrm{Li}$, Liang. (2018). Effect of Prior Knowledge on Attitudes, Behavior, and Learning Performance in Video Lecture Viewing. International Journal of Human-Computer Interaction 35(3):112.doi: $10.1080 / 10447318.2018 .1543086$

\section{DAFTAR PUSTAKA}

